\title{
Sump drainage: a palliative manoeuvre for the treatment of craniopharyngioma
}

\author{
JOHN MILES
}

From the Regional Department of Medical and Surgical Neurology, Walton Hospital, Liverpool

SUMMARY A sump system was used as a palliative manoeuvre in the treatment of four cases of cystic craniopharyngioma. Percutaneous needling of the subcutaneous reservoir enabled the fluid contents of the tumour to be evacuated with considerable therapeutic effect. Radiotherapy was combined with this manoeuvre in two cases. The three successfully treated patients have been followed up for $3 \frac{1}{2}$, five, and $5 \frac{1}{2}$ years. The manoeuvre is not original. It is simple, safe, effective, even in the long term, and worthy of consideration in the treatment of a condition of acknowledged uncertain natural history and surgical difficulty.

Perhaps the greatest difficulty in assessing treatment for craniopharyngioma lies in the uncertainty of its natural history. While often undoubtedly progressive, leading through blindness, hypothalamic insufficiency, and finally coma to death, there is good evidence of a course occasionally much more benign, unpredictable, and even fluctuating (Ross Russell and Pennybacker, 1961; Bartlett, 1971). If this congenital and frequently cystic lesion were always to be progressive, the inevitable deduction would be that early radical surgery would be the treatment of choice. However, even in the most experienced hands the risks of attempting radical surgery are high (Gordy et al., 1949; Matson and Crigler, 1969). Attempted radical surgery for recurrent craniopharyngioma is even more hazardous (Matson and Crigler, 1969; Katz, 1975).

In certain circumstances total extirpation is unlikely. Figure 1 illustrates an extremely extensive, calcified tumour, while Figs. 5 and 6 show an awkwardly placed tumour which is partly within the third ventricle; both these might well be considered to be not totally resectable.

This operative difficulty is particularly frustrating when it is known that at least $50 \%$ of all craniopharyngiomas are substantially cystic and that evacuation of this cyst alone would provide immediate relief of symptoms and signs.

In the past, in this knowledge, evacuation of the fluid contents has been undertaken by repeated cannulation or repeated craniotomy. It is as an extension of this method that I have used a sump drainage

system so that the fluid contents of the craniopharyngioma might be more readily accessible for aspiration.

At initial operation, either by burr hole or craniotomy, a tube is placed in the cyst and led out to a closed reservoir in the subcutaneous position, seated in a burr hole. Repeated percutaneous aspiration from this reservoir is now possible.

When I had used this system for the second time in November 1970, I discovered that a similar system? had been reported by Fox in 1967. The immediate result of implanting four such systems was reported to the Meeting of the Society of British Neurological Surgeons in Liverpool in 1972. Publication of this material has been delayed, until now, to allow of a reasonable follow-up period, obligatory in the management of craniopharyngioma.

\section{Case 1}

D. N., a 17 year old girl, was admitted to hospital in May 1969, blind, deaf, and somnolent. Five years previously she had presented with obstructive hydrocephalus and had her suprasellar tumour explored. A solid craniopharyngioma was found on needling. A ventriculocisternostomy appeared adequately to have relieved the hydrocephalus. The present deterioration had occurred gradually over a period of one year.

Radiological examination of the skull showed the calcification illustrated in Fig. 1. In spite of the unlikelihood of there being any significant cyst, and with the full co-operation of the parents, it was decided to re-explore the tumour, this time by a 


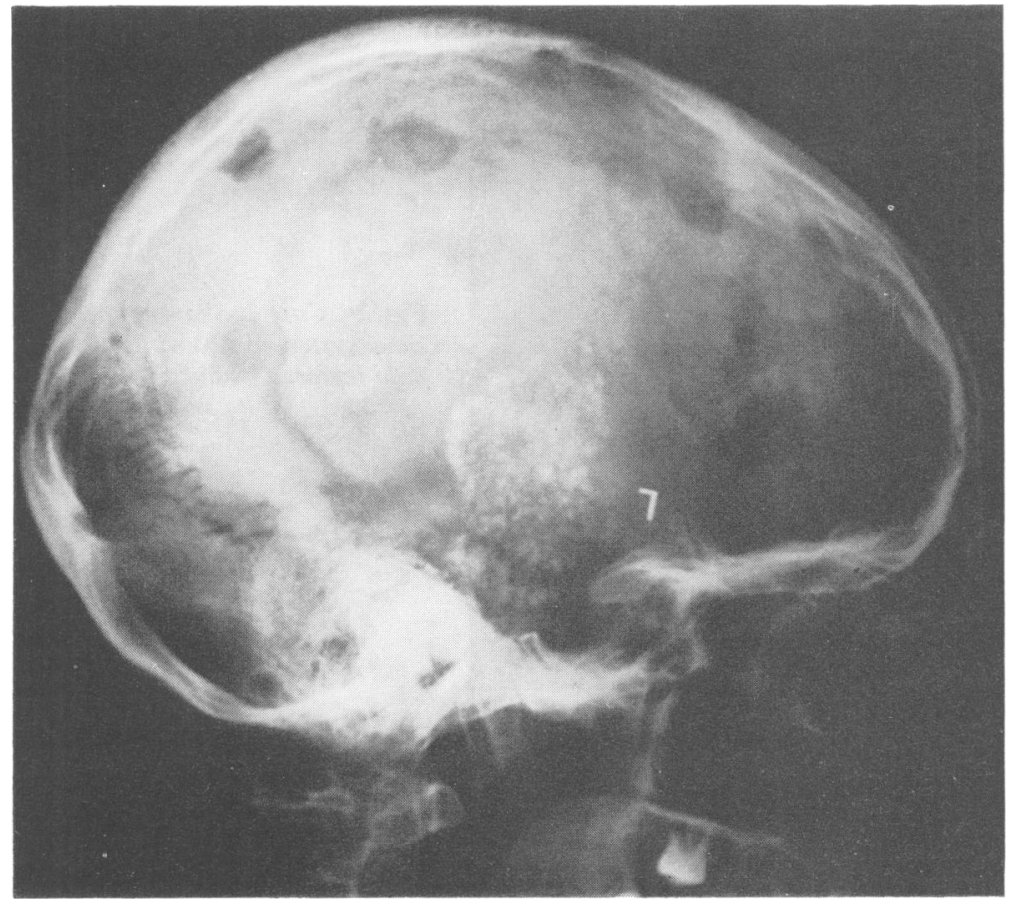

Fig. 1 Case 1. At the time of second presentation, showing the extremely extensive calcification.

temporal craniotomy and transtentorial approach to the posterior parts of the tumour. A cystic cavity was found at $0.5 \mathrm{~cm}$ depth within the hard, calcified tumour capsule and a silicone plastic tube with three side holes was inserted to a depth of $2.5 \mathrm{~cm}$. An Ommaya reservoir was connected to this tube and left in one of the burr holes. Before closing the skin, $20 \mathrm{ml}$ of typical, golden, craniopharyngioma fluid was aspirated from the reservoir.

There was an immediate improvement in her level of consciousness, and she was able to hear and communicate. Before she was discharged I attempted percutaneous aspiration from the reservoir but could obtain no fluid. I encountered great difficulty in determining when the needle tip was actually within the cavity of the reservoir.

Over the next three months she gradually deteriorated, and further attempts at percutaneous aspiration encountered the same uncertainty of position and no fluid. She died at home and no necropsy was undertaken.

\section{Case 2}

T. J., a 22 year old driver, was admitted to the Queen Elizabeth Hospital, Birmingham, with deterioration of vision present for three months. Two years previously he had accidently noticed impairment of vision in the right eye. Investigation revealed a suprasellar mass that was explored by craniotomy, uncapped, and its mainly fluid contents evacuated. His vision returned to normal after this procedure. At readmission his visual acuity was reduced in the left eye to finger counting and in the right eye to Snellen 6/9. He had a large centrocaecal scotoma in the left eye and an upper temporal quadrantic field defect in the right.

At re-exploration on 5 November 1970 the tumour was found to contain further cyst fluid and a sump system was set up, but on this occasion a Rickham metal based reservoir was used. Some air was instilled and postoperative skull radiographs were taken (Fig. 2). His visual acuity immediately recovered to $6 / 6$ on the right and $6 / 12$ on the left with normal fields on charting with the Bjerrum screen.

Six weeks after operation his vision in the left eye was found to have deteriorated to 6/24 and an inferior temporal quadrantanopia was present on screening. Percutaneous aspiration was accomplished with ease, the needle tip giving a definite metallic click as it struck the metal cup. Eight millilitres of typical craniopharyngioma fluid were aspirated in increments. Toward the end of the aspiration the patient commented on the sudden clarity of his vision. He complained of an unpleasant dull retroorbital pain as further unsuccessful aspiration was 


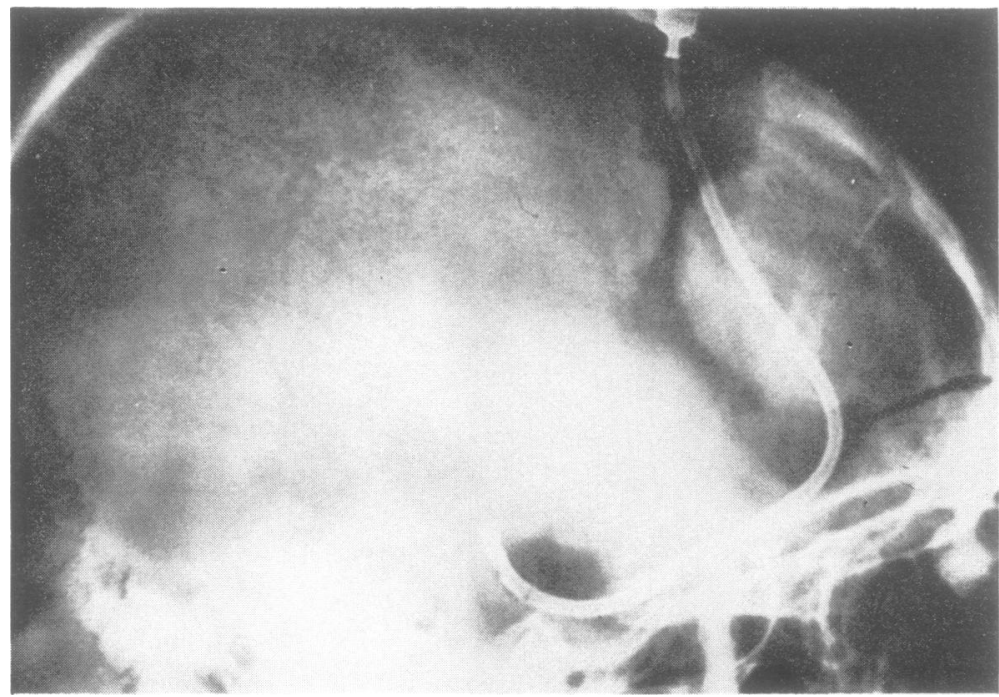

Fig. 2 Case 2. Showing the sump system in situ with the cyst fluid replaced by air.

attempted. His visual acuity two hours later was $6 / 9$ and the peripheral field had returned in the inferior temporal quadrant. Five months later he had again lost vision in the left eye to 6/12 and again lost his inferior temporal visual field. Aspiration now produced $6 \mathrm{ml}$ of the same fluid, the same symptoms at completion, and the improvement in visual acuity and visual field shown in Fig. 3. On this occasion the recording was made 10 minutes after aspiration.

Since that time, and inexplicably, he has remained totally free from visual symptoms, has gradually recovered from mild diabetes insipidus present since his first operation in 1968, and visual assessment shows him to have an acuity of $6 / 5$ bilaterally, and to have no visual field defect on repeated Bjerrum charting.

\section{Case 3}

T. E. P., a 9 year old schoolboy, was admitted to the Midland Centre for Neurosurgery in 1971, severely obtunded, being blind in the right eye, and having some vision only in the left nasal visual field. He had a moderate left hemiparesis. Three years previously he had first presented with headache and visual deterioration. His suprasellar mass had been explored, found to be partly cystic, and was partially evacuated. There was prompt relief of his headache, but he never regained vision in the right eye or in the temporal field of the left eye. One year later he was admitted drowsy with a left hemiparesis, and the same visual signs. Reexploration revealed a massive cyst in the right frontal lobe and from this $160 \mathrm{ml}$ of fluid was aspirated (Fig. 4).
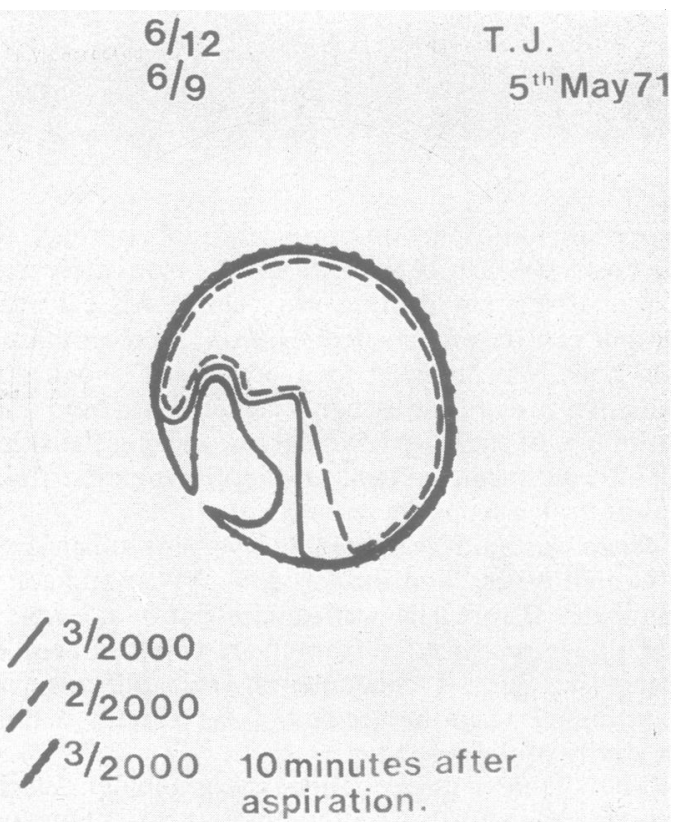

Fig. 3 Case 2. Visual acuity and fields before and 10 minutes after aspiration.

He made a prompt recovery, but within six months he was back in the same state. Burr hole aspiration from the right frontal lobe produced $180 \mathrm{ml}$ of cyst fluid with excellent clinical response.

On 11 November $19705 \mathrm{mCi}$ of radioactive colloidal gold was instilled into the cyst via the frontal 


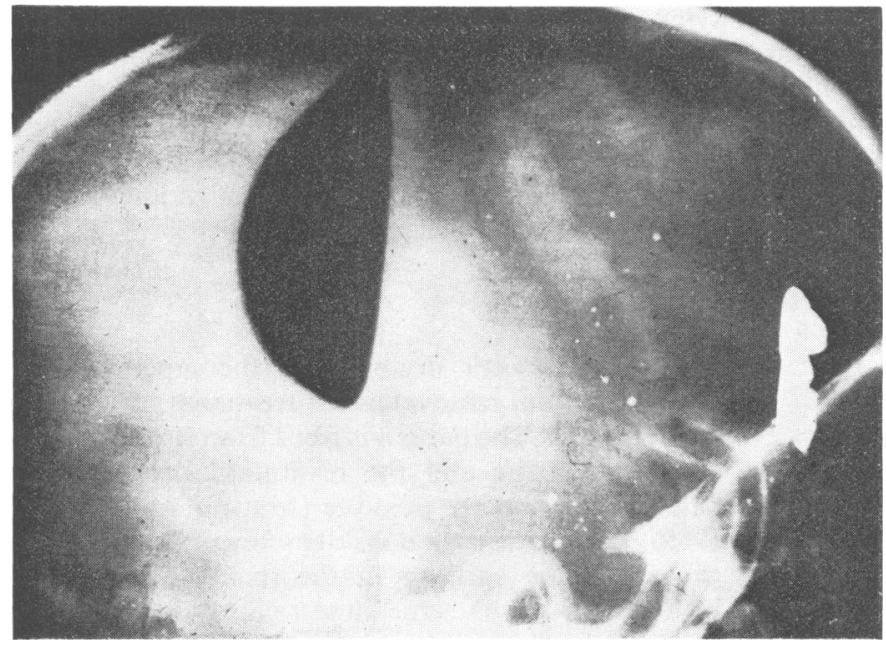

Fig. 4 Case 3. The cyst outlincd by iophendylate and air.

burr hole. Twelve days later $125 \mathrm{ml}$ of fluid was aspirated by cannulation through the frontal burr hole. Three months later in February 1971 he was readmitted as described initially, in the same parlous state.

Through a new frontal burr hole a length of silicone plastic tubing, with side holes, was introduced into the cyst and an attached Rickham reservoir was left seated in the burr hole. Fifty millilitres of cyst fluid were aspirated. He immediately improved. Before discharge, by which time he was alert, continent, feeding himself, and with minimal left hemiparesis, a further $125 \mathrm{ml}$ of fluid was aspirated, percutaneously, from the reservoir.

Over the next four and a half years he has led the life of a normal schoolboy save for the restrictions of having vision only in the nasal field of the left eye. $\mathrm{He}$ has slight spasticity and weakness in the left hand, is short for his age, and at 14 years of age has shown no evidence of secondary sexual development. He has given no evidence to suggest the need for further aspiration.

\section{Case 4}

H. J., a 40 year old pipe-lagger, presented to the Regional Department of Medical and Surgical Neurology, Liverpool, in July 1972 with a story of having rapidly developing headache and confusion. He was disorientated with slight dysphasia and a mild right hemiparesis. He had papilloedema and ventricular enlargement on carotid angiography. Cannulation of the right hemisphere for ventriculography revealed yellow fluid with cholesterol crystals typical of craniopharyngioma, apparently in the region of the third ventricle. This alone achieved complete restitution of his neurological state.

Pneumoencephalography showed that there was a small mass apparently within the substance of the hypothalamus and in the third ventricle. Pneumoencephalography after a further two months (Fig. 5) showed this mass to have enlarged. I considered sump drainage to be the treatment of choice for a craniopharyngioma in this position. Through a right frontal craniotomy and a subfrontal approach no abnormality was present at or beneath the optic chiasma. When the lamina terminalis was exposed it appeared normally translucent but through it I could see flecks of calcification. The lamina terminalis was punctured and typical craniopharyngioma fluid released. A silicone plastic tube with two side holes was inserted and led out to a Rickham reservoir seated in a burr hole. Fifteen millilitres of fluid were aspirated from the reservoir before skin closure.

He recovered and was free from neurological signs at discharge. At three months, and on three other occasions in the next 15 months, he gradually developed slight frontal headache, had deterioration of visual acuity to $6 / 18$, and had lost some left homonymous visual field on charting.

On each occasion $8-10 \mathrm{ml}$ of fluid was aspirated with immediate relief of symptoms and clearance of signs.

Fifteen months after operation, I considered it necessary to attempt to suppress secretion in this cyst. Dr Roger Ryall, of the Department of Radiotherapy, Clatterbridge Hospital, advised on external radiation of the well-delineated lesion (Fig. 6).

Radiotherapy was undertaken without complication. Three months after radiotherapy the patient 
was symptom-free, but had a very slight visual field defect. When further percutaneous aspiration was undertaken, approximately $1 \mathrm{ml}$ of thick white catarrhal material was all that could be obtained. At this point, he complained of slight retro-orbital headache as he had at the termination of each previous aspiration. There was immediate improvement in his visual field.

In the two years since radiotherapy, he has had no

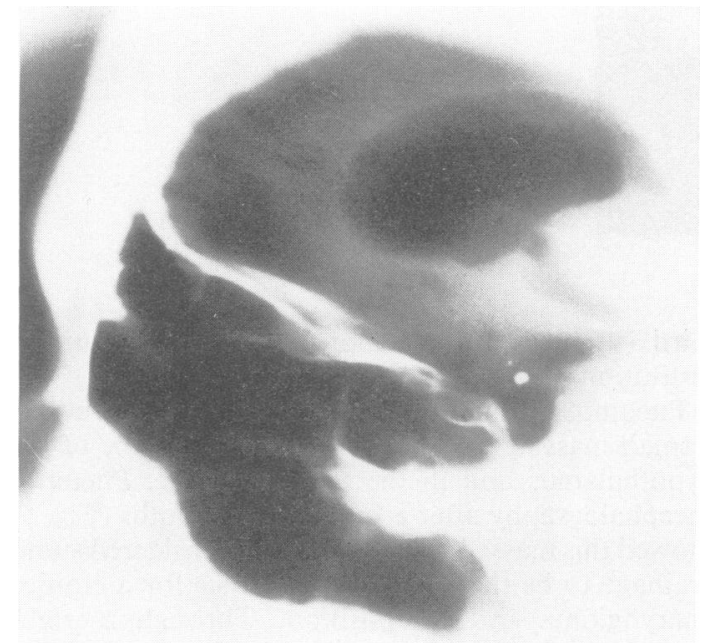

Fig. 5 Case 4. Pneumoencephalography showing the craniopharyngioma to be within the third ventricle and not in the suprasellar position. symptoms or signs to suggest recurrence of fluid, and had no aspirations. His visual acuity and fields are normal. Three months ago he developed two isolated grand mal epileptic fits, with prompt recovery and no recurrence since being on anticonvulsant therapy. No further investigation of these attacks has been undertaken.

\section{Discussion}

There can be little doubt as to the superiority of successful, total removal as the treatment for craniopharyngioma. The patient is freed from further threat to vision or life and the restitution of hormonal balance is distinctly possible (Matson and Crigler, 1969). There is also the considerable satisfaction to be gained by the surgeon in the removal of such a benign, but at the same time treacherous, tumour. With the considerable advantages afforded by the operating microscope and the technique of bipolar coagulation, this satisfaction is being increasingly realised. In the last three years I have totally removed two craniopharyngiomas, each being discrete, small, and in the suprasellar subarachnoid position. Necropsy confirmed that the removal had been total when one patient unfortunately died 18 months after operation, from an unrelated illness.

We cannot, however, deny that the total resection of a craniopharyngioma constitutes a major and dangerous operation. While the mortality of $41 \%$ quoted before adequate steroid replacement therapy was available (Gordy et al., 1949) should not still obtain, it is still substantial, and this is particularly so when the operation is secondary-that is, for recurrent craniopharyngioma. Katz (1975) quotes

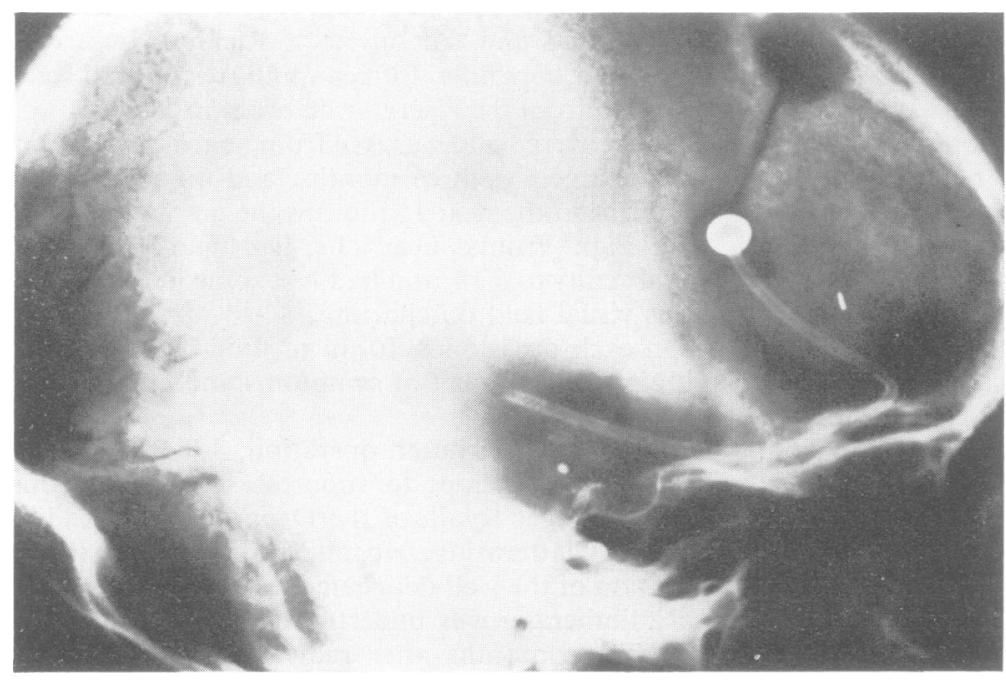

Fig. 6 Case 4. Showing the cavity of the craniopharyngioma within the third ventricle. 
Matson's immediate mortality for secondary operation as $25 \%$ and the ultimate mortality in this group as $71 \%$.

How often do we deceive ourselves on this question of the completeness of the removal? Matson, a surgeon of the highest calibre and integrity, has had recurrences after 'total' removal (Katz, 1975).

Radiotherapy has been advocated in the treatment of craniopharyngioma (Sharma et al., 1974) and in the fourth case, and probably in the third case, it proved to be the definitive treatment. External irradiation has been used (Kramer et al., 1968) with six cases all apparently well, between 13 and 15 years later. Leksell et al. (1967) described the instillation of radioactive phosphorus and yttrium by stereotactic puncturing of the cyst. This treatment appeared to be successful, but there was a mortality of $12.5 \%$. Bond et al. (1965) similarly instilled radioactive gold but concluded that the dose they used had been too great, with necropsy evidence of hypothalamic damage and an eventual mortality in five cases of $80 \%$.

Trippi et al. (1969), using a system similar to ours, instilled $1 \mathrm{mCi}$ of radioactive colloidal chromic phosphate into two craniopharyngiomas. Multiple injections and aspirations were necessary but eventually the returning fluid appeared crystal clear. The patients appeared to be well for the 18 months' follow-up.

As already mentioned, Fox (1967) was the first to use this form of sump drainage in the treatment of cystic craniopharyngioma. He used an Ommaya reservoir and his patient required six aspirations in the seven months of the follow-up.

As far as the cases presented here are concerned, in the first, the proportion of cystic to solid tumour was low and the prospect of substantial response unlikely. There was, however, a definite, immediate response, but from then on I am not sure whether there was no further fluid reaching the reservoir or whether it was that the Ommaya reservoir, in my hands, proved less than satisfactory. Certainly, the metal based, plastic capped, Rickham reservoir has removed such uncertainty, and has proved completely satisfactory.

In the third and fourth cases, as stated, I believe the sump system served only a temporising function, and it was radiotherapy that provided the definitive remedy.

I cannot explain the, apparently complete, success of the sump system in the second case. Should, however, evidence of a recurrence occur in the future all therapeutic options remain open.

\section{Conclusion}

In the circumstances of recurrent cystic craniopharyngioma or of an extremely extensive or par- ticularly awkward craniopharyngioma (such as in case 4) there would seem to be every reason to undertake the relatively simple and hazard-free manoeuvre of establishing a sump drainage system as has been described.

It should relieve, at least in part, the symptoms and signs due to the space taken up by the cyst. It should allow of more accurate assessment of cyst size, though this method of cystography will probably be superseded by EMI scanning. It will allow of the introduction of radioisotopes if that is desired, or other fluids such as perhaps solvents suitable for dissolving the troublesome solid concretions that occur within the craniopharyngioma. It should not seriously complicate later and more definitive surgery, as little or no dissection is normally undertaken. It may even provide temporary relief that will allow time for significant advances in treatment such as those that have occurred recently in the surgery of this region.

I would like to thank Mr Jack Small, of the Midland Centre for Neurosurgery, Smethwick, and Professor Brodie Hughes of the Queen Elizabeth Hospital, Birmingham for allowing me to perform this manoeuvre on the first three cases and for maintaining their follow-up surveillance, and Dr Roger Ryall, of the Regional Department of Radiotherapy, Clatterbridge Hospital, Merseyside, for help with the last case.

\section{References}

Bartlett, J. R. (1971). Craniopharyngioma: summary of 85 cases. Journal of Neurology, Neurosurgery, and Psychiatry, 34, 37-41.

Bond, W. H., Richards, D., and Turner, E. A. (1965). Experiences with radioactive gold in the treatment of craniopharyngioma. Journal of Neurology, Neurosurgery, and Psychiatry, 28, 30-38.

Fox, J. L. (1967). Intermittent drainage of intracranial cyst via the subcutaneous Ommaya reservoir. Journal of Neurosurgery, 27, 272-273.

Gordy, P. G., Peet, M. M., and Khan, E. A. (1949). The surgery of craniopharyngioma. Journal of Neurosurgery, 6, 503-517.

Katz, E. L. (1975). Late results of radical excision of craniopharyngioma in children. Journal of Neurosurgery, 42, 86-93.

Kramer, S., Southland, M., and Mansfield, C. M. (1968). Radiotherapy in the management of craniopharyngiomas. Further experiences and late results. American Journal of Roentgenology, 103, 44-52.

Leksell, L., Backlund, E. O., and Johansson, L. (1967). Treatment of craniopharyngiomas. Acta Chirurgica Scandinavica, 133, 354-350.

Matson, D. D., and Crigler, T. F. (1969). Management of craniopharyngiomas in childhood. Journal of Neurosurgery, 30, 377-390. 
Ross Russell, R. W., and Pennybacker, J. B. (1961). Craniopharyngioma in the elderly. Journal of Neurology, Neurosurgery, and Psychiatry, 24, 1-13.

Sharma, U., Tandon, P. N., Saxena, K. K., Singhal, R. M., and Baruah, J. D. (1974). Craniopharyngioma treated by combination of surgery and radiotherapy. Clinical Radiology, 25, 13-17.
Trippi, A. C., Garnier, J. T., Kassabian, J. T., and Sheldon, C. H. (1969). A new approach to inoperable craniopharyngioma. American Journal of Surgery, 118, 307-310. 